\title{
Refractive errors and visual impairment among children and adolescents in southernmost China
}

\author{
Li Peng ${ }^{1,2+} \mathbb{D}$, Ling Gao ${ }^{3 \dagger}$, Yunyan Zheng ${ }^{1}$, Yanan Dai ${ }^{4}$ and Qing Xie ${ }^{1 *}$ (D)
}

\begin{abstract}
Background: Refractive errors and visual impairment in southernmost China have not been reported previously. We aim to investigate and determine the age-specific prevalence of myopia, hyperopia, astigmatism, and visual impairment based on a large population cross-sectional study in Hainan area of southernmost tropical province in China.

Methods: A population-based sample of 31,524 children aged 6-15 years from Hainan was assessed. Noncycloplegic autorefraction and visual acuity (VA) analyses were performed on all participants and a subgroup of participants undergoing cycloplegia.

Results: Of all participants, 23.0\% presented uncorrected VA (UCVA) was worse than 20/40 in worse eye, 6.0\% presented mild presenting visual acuity impairment (PVAl), 7.0\% presented moderate PVAl, $0.2 \%$ presented severe PVAl in the better eye, and $46.9 \%$ presented abnormal UCVA [worse than $20 / 25(\geq 6,<8$ years old) and worse than $20 / 20$ ( $\geq 8$ years and older)] at least in one eye. The overall prevalence of myopia [spherical equivalent (SE) $\leq-0.50$ D] and high myopia (SE $\leq-6.00$ D) were $46.0 \%, 1.0 \%$ respectively. Hyperopia [SE $\geq+1.00 \mathrm{D}$ ( $\geq 7$ years old) and $\mathrm{SE} \geq+2.00 \mathrm{D}(\geq 6,<7$ years old)] and significant hyperopia (SE $\geq+3.00 \mathrm{D})$ were 4.2 and $0.6 \%$, respectively. Astigmatism [cylinder $\geq 1.00 \mathrm{D}$ ( $\geq 7$ years old) and $\geq 1.75 \mathrm{D}$ ( $\geq 6,<7$ years old)] was found in $31.9 \%$.

Conclusions: Myopia was the most common refractive error in southernmost province in China (Hainan). Its prevalence increased with age, while hyperopia prevalence showed a decreasing trend. However, myopia, especially high myopia prevalence was much lower than in other urban regions across China.
\end{abstract}

Keywords: Refractive errors, Myopia, Hyperopia, Visual impairment, Children and adolescents, Tropical island

\section{Background}

Refractive errors (RE) are the most common cause of visual impairment and disability in children and adolescents worldwide [1]. They can be classified into myopia, hyperopia and astigmatism [2]. Globally, it was estimated that 12.8 million children have visually impairment from uncorrected refractive errors from 2004, and this is set

\footnotetext{
* Correspondence: opht_xq@163.com

${ }^{+}$Li Peng and Ling Gao contributed equally to this work.

'Department of Ophthalmology, Central South University Xiangya School of Medicine Affiliated Haikou Hospital, Haikou 570208, Hainan, China Full list of author information is available at the end of the article
}

to rise with the increasing incidence of myopia [3]. Refractive errors represent an excessive increase in myopia which has huge social, educational, and economic consequences to society, especially for those suffering from high myopia $[4,5]$. Currently, the prevalence of myopia is increasing worldwide [6]. As is well-known, the highest rates of myopia occur in China with over $80 \%$ of the younger generation impacted at present [7], making it a major current concern.

Studies have been performed to excavate the possible factors related to refractive errors [8]. Environmental

(c) The Author(s). 2021 Open Access This article is licensed under a Creative Commons Attribution 4.0 International License, which permits use, sharing, adaptation, distribution and reproduction in any medium or format, as long as you give appropriate credit to the original author(s) and the source, provide a link to the Creative Commons licence, and indicate if changes were made. The images or other third party material in this article are included in the article's Creative Commons licence, unless indicated otherwise in a credit line to the material. If material is not included in the article's Creative Commons licence and your intended use is not permitted by statutory regulation or exceeds the permitted use, you will need to obtain permission directly from the copyright holder. To view a copy of this licence, visit http://creativecommons.org/licenses/by/4.0/ The Creative Commons Public Domain Dedication waiver (http://creativecommons.org/publicdomain/zero/1.0/) applies to the data made available in this article, unless otherwise stated in a credit line to the data. 
and genetic factors have both been implicated $[8,9]$. Some researchers confirmed that time spent outdoors playing is an important environmental factor for preventing myopia [10]. Previous studies have suggested that daylight exposure holds a dose-response relationship with ocular axial elongation, which plays a vital role in reducing myopia [11]. Hainan, the only tropical island and province in China, stretches from $3.30^{\circ} \mathrm{N} \sim 20.07^{\circ} \mathrm{N}$ latitude with the longest daylight exposure in China. The analysis of visual refractive errors in this isolated island has barely been reported to date. Therefore, it is important to identify the prevalence in Hainan children and adolescents. The purpose of this study is to evaluate the prevalence of myopia, hyperopia, astigmatism and visual impairment in the only tropical region in China. It aims to contribute new data on refractive errors and visual acuity for this population.

\section{Methods}

\section{Study population}

This large population cross-sectional study was approved by the research ethics committees of Central South University Xiangya School of Medicine, Affiliated Haikou Hospital and adhered to the tenets of the Declaration of Helsinki. Written informed consent and assent were obtained from their parent or legal guardian of all participants. Prior to enrolling school children and adolescents, the purpose and methods of this study were explicated by the investigators. This was a cross-sectional study conducted from May 2018 to July 2018 in Haikou, a provincial capital of about 2.2 million people in Hainan province, P. R. China, and it stretches from $19.32 \mathrm{~N}$ $20.05 \mathrm{~N}$ latitude with the long daylight exposure in China.

Using randomized method, MeiLan District was randomly selected from 4 districts in the Haikou city, 12 primary schools were selected from 30 primary schools and 7 junior middle schools were selected from 16 junior middle schools. All students from the selected schools were invited to participate. In this study children and adolescents stands for boys and girls aged between 6 and 15 years old. The inclusion criteria for our study were as follows: (1) age between 6 and 15 years; (2) with no congenital abnormalities; (3) Chinese Han Nationality Students; (4) an informed consent was obtained by the parents or legal guardian. The reasons for exclusion from the analysis of refraction were failure to complete the examination, previous ophthalmic surgery, wearing intraocular lenses, ocular diseases (ocular trauma, cataracts, glaucoma, optic neuropathy) or ocular injuries caused the significant refractive error. Of 31,780 eligible students, 31,524 students took part in this study $(99.20 \%$ participation rate).
All the participants accepted the UCVA testing, refractive error measurement, slit lamp microscope examination, cover-uncover test, alternate cover test and pupil fundus examination. Before test of visual acuity, students were asked to take off glasses or contact lens. Uncorrected visual acuity (UCVA) was tested for each eye by trained doctors under bright daylight with a measured distance of five meters, by using the standard Logarithmic visual acuity $\mathrm{E}$ chart. The values were converted to Snellen for subsequent analyses. The children and adolescents underwent all examinations by two trained ophthalmologists and auto-refractometry was conducted by two experienced senior optometrists. Refractive error (RE) of each eye was measured without cycloplegia at least three times via performing an automatic refractometer (NIDEK, ARK-1, Japan). Three readings of refractive error were taken from each eye and their average was entered for analysis. Repeated measurements were performed if one measured outcome deviated from the other two by more than $0.50 \mathrm{D}$.

In addition, for better quality control, the professional engineers calibrated the autorefractors every day to minimize the measuring refractive error. About $5 \%$ of the students were randomly selected to perform the repeated test of refraction. Data Recording were double entered into Microsoft Excel spreadsheets, meanwhile, by checking the original paper records against the database was conducted to resolve the differences.

\section{Population subgroup for a cycloplegic autorefraction study}

The refraction results were considered to be influenced by active accommodation responses in children with non-cycloplegic autorefraction [1]. A small fraction of these participants with accepting parents were assigned to cycloplegia measurement before and after cycloplegia in a pilot study. Cycloplegia assessment was performed using $1 \%$ cyclopentolate eye drops. Refractive error measurements were performed with same protocol as above before and after cycloplegia. A total of 1,006 students participated in the subgroup for a cycloplegic autorefraction study, of these 546 were boys and 457 girls.

\section{Definitions of myopia, hyperopia and astigmatism}

Spherical equivalent refractive errors were counted as the sphere power plus $1 / 2$ of the cylinder power $(\mathrm{SER}=$ sphere $+1 / 2$ cylinder). Considering the non-cycloplegic autorefractor was applied to measure the refractive error, which tended to over-measure the myopic magnitude, especially in in young children, we defined myopia using combination of spherical equivalent and UCVA. Myopia was defined as spherical equivalent $(\mathrm{SE}) \leq-0.50$ diopter (D) and UCVA 20/25 or worse in at least one eye. High myopia was defined as spherical equivalent $\leq-$ 
6.0 diopters (D) and UCVA 20/25 or worse. It was found that the UCVA was taken into consideration can improve the accuracy of myopia using non-cycloplegic autorefractor refractive error. Non-myopia was defined as follows, SE between -0.50 to $+1.00 \mathrm{D}$ and no glasses or ophthalmic history [12]. Since UCVA was a study factor to consider in all children, UCVA 20/20 in both eyes was not used for study exclusion. Hyperopia was defined as $\mathrm{SE} \geq+1.00 \mathrm{D}$ ( $\geq 7$ years old) and $\mathrm{SE} \geq+2.00 \mathrm{D}(\geq 6$, $<7$ years old) in at least one eye for the primary analysis. Cylindrical refractive error was classified as positive correcting cylinder form. Astigmatism was defined as absolute values of cylindrical refractive error in at least one eye: $\geq 1.00 \mathrm{D}$ ( $\geq 7$ years old) and $\geq 1.75 \mathrm{D}(\geq 6,<7$ years old). When one eye was myopic and the other hyperopic, the participant was considered both as a myope and as a hyperope. If a refractive error was present only in one eye, the participant was still categorized into the appropriate eye group for each condition in the analysis. Meanwhile, hyperopia ( $\mathrm{SE} \geq+3.00 \mathrm{D}$ ) were also calculated and presented in this study for further research.

\section{Definition of abnormal UCVA}

Abnormal UCVA was defined as UCVA worse than 20/ 25 ( $\geq 6,<8$ years old) and worse than $20 / 20$ ( $\geq 8$ years and older) in at least one eye for its clinical diagnosis. Conversely, in all other conditions it was defined as normal UCVA.

\section{Definition of presenting visual acuity impairment}

Based on standard WHO definition, visual impairment reported as presenting visual acuity (PVA). The PVA was considered the uncorrected VA for subjects who do not have corrective eyeglasses. Presenting visual acuity impairment (PVAI) was classified as mild visual impairment, moderate visual impairment and severe visual impairment. Mild visual impairment, Moderate visual impairment and severe visual impairment were defined as presenting visual acuity between $6 / 12$ to $6 / 18,6 / 18$ to $6 / 60$, and $6 / 60$ to $3 / 60$ in the better eye.

\section{Statistical analysis}

Prevalence was calculated as the percentage of participants with the particular type of refractive error to the total number of children who successfully completed refraction for at least one eye. Results are showed for 3 age groups from 6 to 15 years old. R statistical analysis package (version 3.5.3) was used to statistically analyze the data with a 0.05 significance level for probability (p). Confidence intervals (CI) presented for proportions are exact binomial 95\% confidence intervals. No missing data were found.

\section{Results}

Population characteristics

Of 31,780 eligible students, 31,524 children and adolescents participated in this study and completed all the clinical eye examinations (99.2\% participation rate). 17, 794 were boys and 13,730 were girls. The proportion of male participants was a little higher than that of female participants $(56.4 \%$ vs.43.6\%, $P<0.0001)$. Mean age of the participants was $9.73 \pm 2.42$ years (range 6 to 15 years). The participants were grouped into three according to their ages $(\geq 6,<9$ years old for group6-8; $\geq$ $9,<12$ years old years for group $9-11 ; \geq 12$; and $\leq 15$ years old for group12-15). The number of children were 11, $277,12,292$, and 7,955 for the three groups, respectively. The demographic characteristics of the participants are demonstrated in Fig. 1a, b.

\section{Abnormal UCVA}

Abnormal UCVA was observed in 46.9\% (CI: 46.4-47.5\%) of all the participants $(14,799 / 31,524), 25.7 \%$ (CI: 24.9$26.5 \%)$ in group6-8 (2,901/11,277), $55.4 \%$ (CI: $54.5-56.2 \%)$ of group9-11 (6,806/12,292) and 64.0\% (CI: 63.0-65.1\%) of group12-15 $(5,092 / 7,955)$ (Table 1 and Fig. 2a).

\section{Visual acuity impairment}

About 23.0\% (CI: 22.5-23.5\%) of all participants had UCVA worse than $20 / 40$ in worse eye $(7246 / 31,524)$, 6.0\% (CI:5.6-6.4\%) in group6-8(677/11,277), $27.2 \%$ (CI: $26.5-28.0 \%)$ of group $9-11(3349 / 12,292)$ and $40.5 \%(\mathrm{CI}$ : $39.4-41.6 \%)$ in group12-15 (3,220/7955) (Fig. 2b). Differences were seen between groups. The results showed a trend of worsening UCVA with age.

Mild presenting visual acuity impairment (PVAI) was seen in $6.0 \%$ (CI: 5.7-6.2\%) of all the participants in the better eye, $2.0 \%$ (CI: $0.18-0.23 \%$ ) in group6-8, $7.2 \%$ (CI: $6.8-7.7 \%$ ) in group9-11, 9.6\% (CI: $8.9-10.2 \%$ ) in group12-15, respectively. Moderate PVAI was seen in $7.0 \%$ (CI: $6.8-7.3 \%$ ) of all the participants in the better eye, $0.9 \%$ (CI: $0.7-1.1 \%$ ) in group6-8, 8.3\% (CI: 7.8$8.8 \%$ ) in group9-11, $13.7 \%$ (CI: $13.0-14.5 \%$ ) in group1215 , respectively. Severe PVAI was seen in $0.2 \%$ (CI: $0.1-$ $0.2 \%$ ) of all the participants in the better eye, $0.0 \%(\mathrm{CI}$ : $0.0-0.0 \%)$ in group6-8, $0.2 \%$ (CI: $0.1-0.2 \%)$ in group9$11,0.4 \%$ (CI: $0.3-0.6 \%$ ) in group12-15, respectively (Table 1 and Fig. 2c, d, e).

\section{Refractive error varies with age}

The overall mean SE was -1.16D (1.43), for right eyes and -1.13D (1.56) for left eyes. The mean SE was -0.98 D (1.37) in group6-8, -1.16 D (1.42) in group9-11, and -1.39D (1.50) in group12-15 for the right eyes. The mean SE differences between the three age groups were statistically significant $(\mathrm{p} 1,2,3<0.001)$, which indicated negative SE increase with age (Table 1 and Fig. 3). 

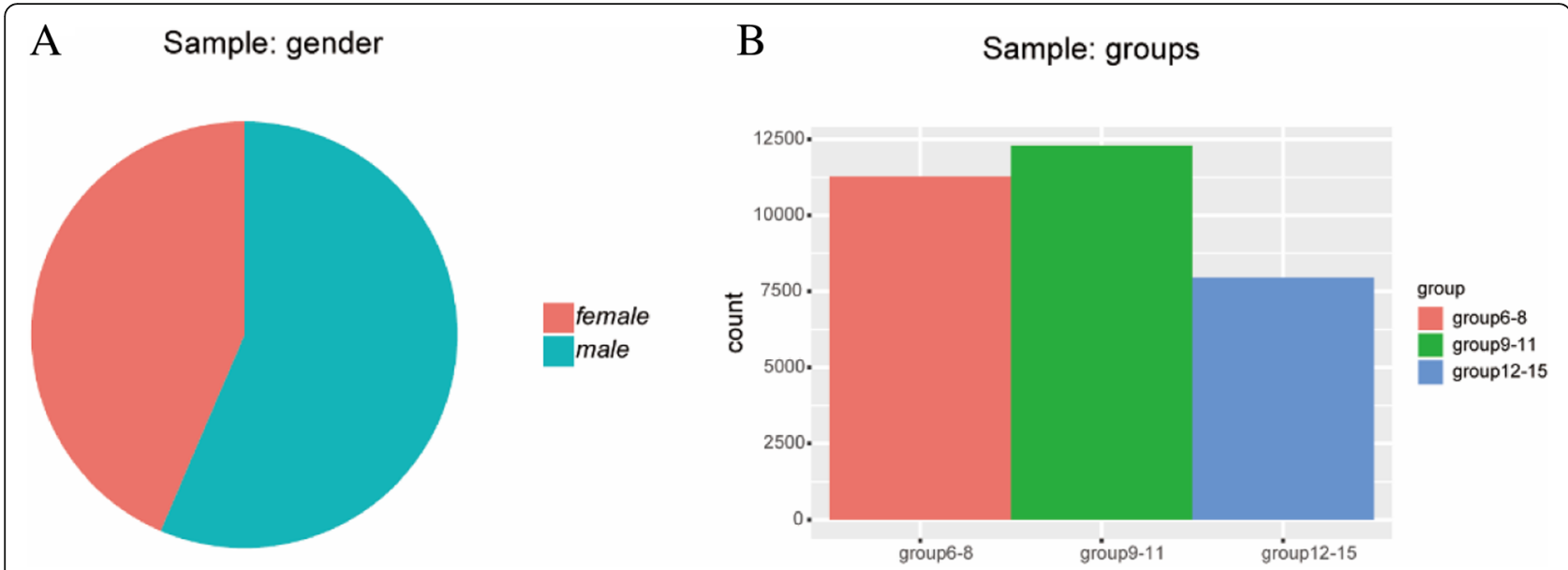

Fig. 1 Distribution of sample by gender $\mathbf{a}$ and age group $\mathbf{b}$. The proportion of male participants was a little higher than that of female participants $(56.4 \%$ vs. $43.6 \%, P<0.0001)$

\section{Prevalence of myopia, hyperopia and astigmatism}

Table 2 summarizes the prevalence of myopia, hyperopia, and astigmatism determined in each age group between 6 to 15 years. The overall prevalence rates of myopia and hyperopia were $46.0 \%$ (CI: 45.4-46.5\%) and 4.2\% (CI:4.0-4.4\%). Moreover, myopia and hyperopia prevalence rates were $31.2 \%$ (CI: $30.4-32.1 \%$ ) and $5.6 \%$ (CI: $5.2-6.0 \%$ ) in group6-8, 50.1\% (CI: $49.2-51.0 \%$ ) and $3.6 \%$ (CI: $3.3-3.9 \%$ ) in group9-11, 60.5\% (CI:59.5-61.6\%) and 3.2\% (CI:3.4-4.3\%) in group12-15, respectively. Differences were seen in myopia and hyperopia prevalence between groups. Both were associated with age. The overall prevalence of high myopia was $1.0 \%$ (CI: $0.9-$ $1.1 \%$ ); $0.2 \%$ (CI: $0.1-0.3 \%$ ) in group6-8, $1.0 \%$ (CI: $0.8-$ $1.1 \%$ ) in group9-11 and $2.1 \%$ (CI: $1.8-2.4 \%$ ) in group1215. The overall prevalence of significant high hyperopia $(\mathrm{SE} \geq+3.00 \mathrm{D})$ was $0.6 \%$ (CI: $0.5-0.7 \%) ; 0.7 \%$ (CI: $0.5-$ $0.8 \%$ ) in group6-8, $0.6 \%$ (CI: $0.5-0.7 \%)$ in group9-11 and $0.6 \%$ (CI: $0.4-0.7 \%$ ) in group12-15. The overall prevalence of astigmatism was $31.9 \%$ (CI: 31.4-32.4\%); $29.9 \%$ (CI: $29.0-30.7 \%$ ) in group6-8, 32.7\% (CI: $31.9-33.5 \%)$ in group9-11 and 33.4\% (CI: 32.4-34.4\%) in group12-15.
Figure 4 illustrates the prevalence of myopia, hyperopia and astigmatism by year of age in 6 to 15-year-olds. Myopia and high myopia prevalence appeared increased across the age range with a significant trend, but this contrasted with hyperopia prevalence. Results for astigmatism revealed that prevalence appeared relatively stable with no significant trend. Different SE statuses were also calculated (Table 2, Fig. 4).

\section{Refractive errors prevalence}

Refractive errors include myopia, hyperopia and astigmatism. If at least one of three conditions was met, then participants were categorized as refractive errors. The overall prevalence rates of prevalence of refractive errors was $59.6 \%$ (CI:59.0-60.1\%).

\section{Cycloplegic autorefraction subgroup study results}

About 1,003 children and adolescents included in the subgroup of participants 546 were boys and 457 were girls with a mean age of $9.90 \pm 2.30$. (median:10 years; range: $6-15$ years). The overall mean SE was $-1.27 \pm$ $1.43 \mathrm{D},-0.90 \pm 1.66 \mathrm{D}$ for right eyes and $-1.24 \pm 1.5 \mathrm{D}$,

Table 1 Table of presenting visual acuity. Mean SE (standard deviation, SD) in diopters [D]

\begin{tabular}{|c|c|c|c|c|c|c|c|}
\hline $\begin{array}{l}\text { Age } \\
\text { groups }\end{array}$ & $\mathrm{n}$ & $\begin{array}{l}\text { Mild PVAI (Cl) } \\
\text { (\%) }\end{array}$ & $\begin{array}{l}\text { Moderate } \\
\text { PVAI (CI) (\%) }\end{array}$ & $\begin{array}{l}\text { Severe } \\
\text { PVAI (Cl) } \\
(\%)\end{array}$ & $\begin{array}{l}\text { Abnormal } \\
\text { UCVA } \\
\text { (CI) (\%) }\end{array}$ & $\begin{array}{l}\text { UCVA worse than } 20 / 40 \text { in worse eye }(\mathrm{Cl}) \\
\text { (\%) }\end{array}$ & $\begin{array}{l}\text { Mean } \\
\text { SE[D] }\end{array}$ \\
\hline $6-8$ & $\begin{array}{l}11 \\
277\end{array}$ & $2.0(0.18-0.2)$ & $0.9(0.7-1.1)$ & $\begin{array}{l}20.0(0.0- \\
0.0)\end{array}$ & $5.7(24.9-26.5)$ & $6.0(5.6-6.4)$ & $-0.98 \pm 1.37$ \\
\hline $9-11$ & $\begin{array}{l}12 \\
292\end{array}$ & $7.2(6.8-7.7)$ & $8.3(7.8-8.8)$ & $0.2(0.1-0.2)$ & $55.4(54.5-56.2)$ & $27.2(26.5-28.0)$ & $-1.16 \pm 1.42$ \\
\hline $12-15$ & 7955 & 9.6 (Cl: 8.9-10.2) & $\begin{array}{l}13.7(13.0- \\
14.5)\end{array}$ & $0.4(0.3-0.6)$ & $64.0(63.0-65.1)$ & $40.5(39.4-41.6)$ & $-1.39 \pm 1.50$ \\
\hline Total & $\begin{array}{l}31 \\
524\end{array}$ & $6.0(5.7-6.2)$ & $7.0(6.8-7.3)$ & $0.2(0.1-0.2)$ & $46.9(46.4-47.5)$ & $23.0(22.5-23.5)$ & $-1.16 \pm 1.43$ \\
\hline
\end{tabular}




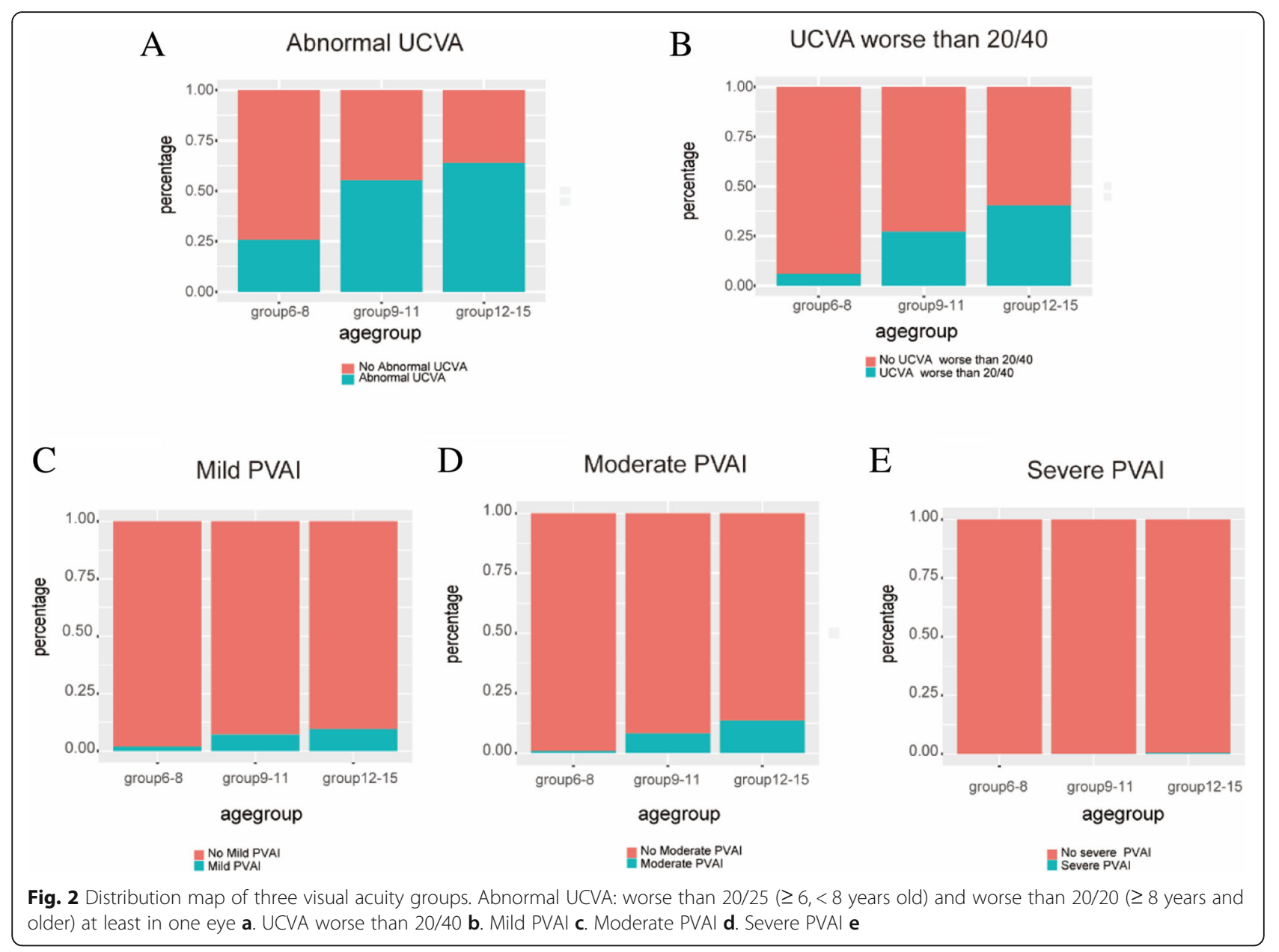

$-0.84 \pm 1.75 \mathrm{D}$ for left eyes before and after cycloplegia respectively. The average difference of SE was $-0.37 \pm$ $0.85 \mathrm{D}$ for right eyes and $-0.40 \pm 0.84 \mathrm{D}$ for left eyes before and after cycloplegia.

\section{Discussion}

Based on the data from large population-based multi-age group studies, we presented prevalence estimations for myopia, hyperopia and astigmatism in Hainan, the tropical island of China with children aged 6 to 15 years old. This is the first report about refractive errors in this emblematic population of children and adolescents in farthest south China. It has revealed myopia to be the most common type of refractive error.

In our study, we found that prevalence of myopia, high myopia and uncorrected visual acuity impairment was lower in the first 3 years of primary school, but increased with age and grade as intensive continuing education increased. However, hyperopia prevalence declined with age. The average SE results were $-0.98 \mathrm{D}$ (1.37), -1.16 D (1.42), and -1.39D (1.50) in the above three age groups respectively. In addition, low myopia is the most common form of myopia, but the prevalence of high myopia increased with advancing age.

Therefore, compared with recently published 5 year child and adolescent myopia data from other countries, the prevalence of myopia in our sample was significantly higher than Netherlands (2.4\%) [9], Saudi Arabia (2.7\%) [13], Norway (13.0\%) [7], Colombia (14.9\%) [14], North India (21.1\%) [6], Denmark (17.9\%) [15], Spain (20.0\%) [11], and Poland (16.33\%) [16]. However, it is similar to France (42.7\%) [17], but lower than in Korea (51.9\%) [18] (see Table 3). Compared with different regions across China, the prevalence of myopia in our study within the same age range of children was lower than that of Feng Hua (87.65\%, Eastern China) [19], Guangzhou (69.9\%, Southern China) [20], Beijing (70.9\%, Northern China) [21], Qingdao (52.02\%, Eastern China) [22], Chongqing (54.9\%, Western China) [23], and Tianjin (53.9\%, Northern China) [24], but higher than Mangshi (35.9\%,Western Rural China) [25], and Tibet (28.51\%, Plateau of China) [26] (Table 3) (Fig. 5).

The overall prevalence of high myopia was very low (1.0\%), lower than many studies with a similar age group, such as studies from Korea (5\%) [18], Spain 


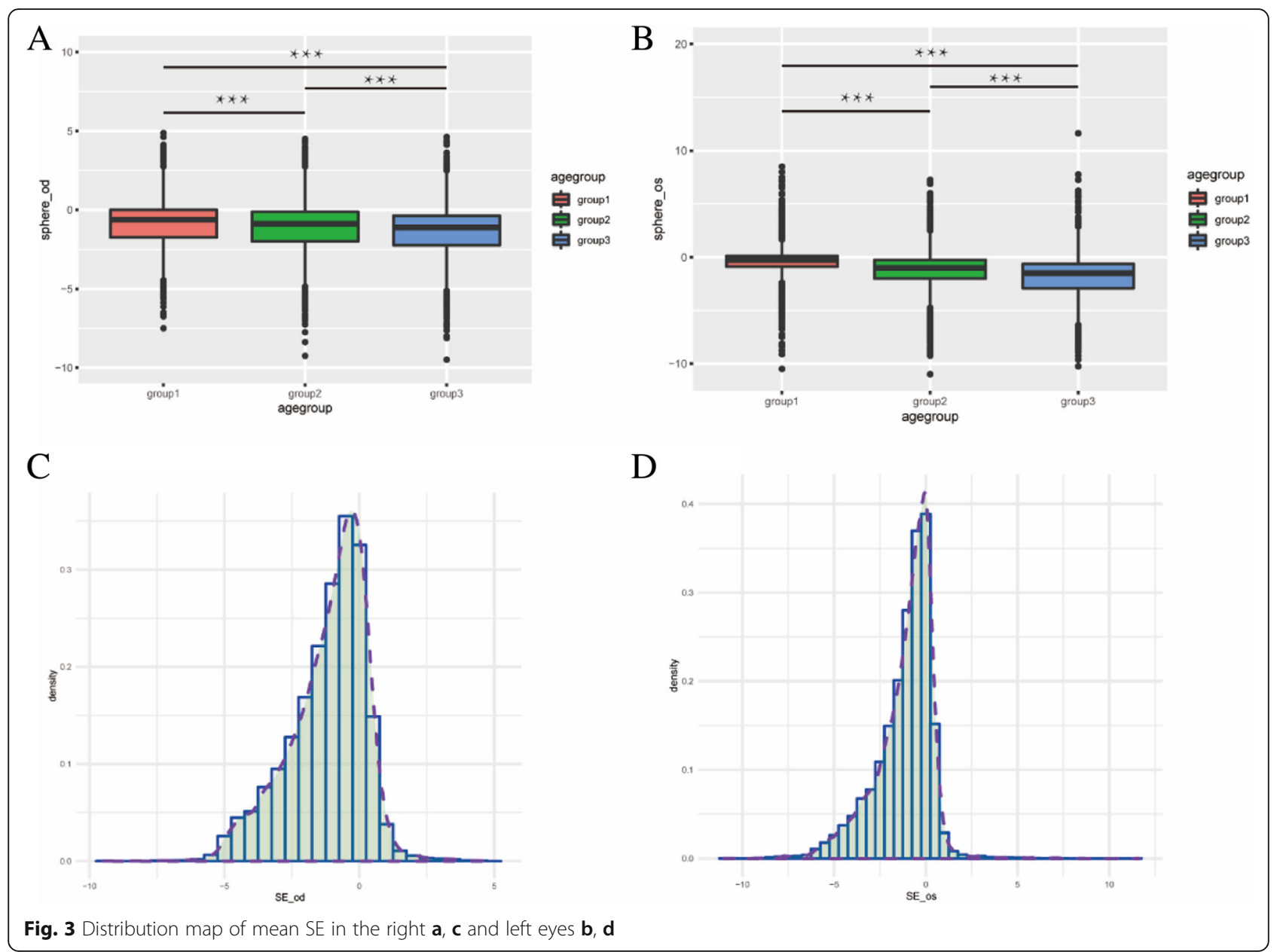

Table 2 Prevalence of myopia, hyperopia, astigmatism and the distribution of different SE

\begin{tabular}{|c|c|c|c|c|c|c|c|}
\hline $\begin{array}{l}\text { Age } \\
\text { groups }\end{array}$ & & $\mathrm{n}$ & $\begin{array}{l}\text { Myopia \% (Cl) }(\mathrm{SE} \leq- \\
0.50 \mathrm{D})\end{array}$ & $\begin{array}{l}\text { Myopia } \\
\%(\mathrm{CI}) \\
\text { (SE } \leq- \\
6.00 \mathrm{D})\end{array}$ & $\begin{array}{l}\text { Hyperopia\%(Cl) }(\mathrm{Cl}) \\
\left(\mathrm{SE}^{*}\right)\end{array}$ & $\begin{array}{l}\text { Hyperopia\%(Cl) }(\mathrm{SE} \geq+3.00 \\
\text { D) }\end{array}$ & $\begin{array}{l}\text { Stigmatism\%(Cl) } \\
\left(\left.\mathrm{Cy}\right|^{*}\right)\end{array}$ \\
\hline \multirow[t]{3}{*}{$6-8$} & All & $\begin{array}{l}11 \\
277\end{array}$ & $31.2(30.4-32.1)$ & $0.2(0.1-0.3)$ & $5.6(5.2-6.0)$ & $0.6(0.5-0.8)$ & $29.9(29.0-30.7)$ \\
\hline & Femal & 5078 & $32.7(31.4-34.0)$ & $0.2(0.1-0.3)$ & $5.6(4.9-6.2)$ & $0.7(0.4-0.9)$ & $28.6(27.4-29.8)$ \\
\hline & Male & 6199 & $30.0(28.9-31.1)$ & $0.2(0.1-0.3)$ & $5.6(5.1-6.2)$ & $0.7(0.5-0.9)$ & $30.9(29.8-32.1)$ \\
\hline \multirow[t]{3}{*}{$9-11$} & All & $\begin{array}{l}12 \\
292\end{array}$ & $50.1(49.2-51.0)$ & $0.93(0.8-1.1)$ & $3.6(3.3-3.9)$ & $0.6(0.5-0.7)$ & $32.7(31.9-33.5)$ \\
\hline & Femal & 5366 & $55.1(53.8-56.4)$ & $1.1(0.8-1.4)$ & $3.4(2.9-3.8)$ & $0.6(0.4-0.8)$ & $31.8(30.6-33.1)$ \\
\hline & Male & 6926 & $46.2(45.0-47.4)$ & $0.8(0.6-1.0)$ & $3.8(3.4-4.3)$ & $0.6(0.4-0.8)$ & $33.4(32.3-34.5)$ \\
\hline \multirow[t]{3}{*}{$12-15$} & All & 7955 & $60.5(59.5-61.6)$ & $2.10(1.8-2.4)$ & $3.2(2.8-3.6)$ & $0.6(0.4-0.7)$ & $33.4(32.4-34.4)$ \\
\hline & Femal & 3286 & $69.1(67.6-70.7)$ & $2.7(2.2-3.3)$ & $5.4(3.1-4.4)$ & $0.8(0.5-1.1)$ & $32.9(31.3-34.5)$ \\
\hline & Male & 4669 & $54.4(53.1-55.9)$ & $1.7(1.3-2.0)$ & $2.8(2.3-3.3)$ & $0.5(0.3-0.6)$ & $33.8(32.4-35.1)$ \\
\hline Total & & $\begin{array}{l}31 \\
524\end{array}$ & $46.0(45.4-46.5)$ & $1.0(0.9-1.1)$ & $4.2(4.0-4.4)$ & $0.6(0.5-0.7)$ & $31.9(31.4-32.4)$ \\
\hline
\end{tabular}




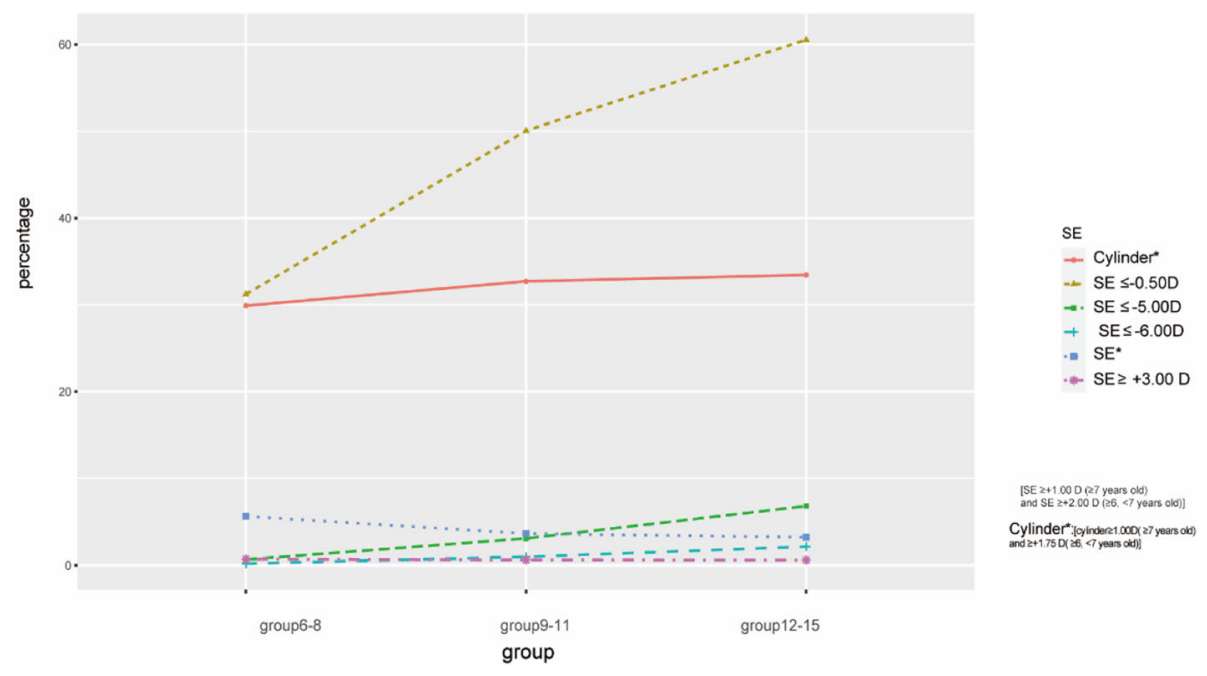

Fig. 4 Changes of distribution lines of myopia, hyperopia, astigmatism and the distribution of different SE with age groups. Locally weighted regression lines derived for prevalence of myopia (SE $\leq-0.50 \mathrm{D}, \leq-5.00 \mathrm{D}, \leq-6.00 \mathrm{D}$ ), hyperopia (SE*), Significant hyperopia (SE $\geq+3.00 \mathrm{D})$ and astigmatism (cylinder*) as a function of age group for Hainan children and adolescents

Table 3 Summary of myopia prevalence (\%) from this study and from other studies published in recent 5 years, matched on myopia definition and best matched on age

\begin{tabular}{|c|c|c|c|c|c|c|c|}
\hline Country & Age (years) & $\mathrm{n}$ & Myopia\% ( $\leq-0.50 \mathrm{D})$ & High Myopia $(\leq-6.00 \mathrm{D})$ & Hyperopia\% $(\geq+0.50 \mathrm{D})$ & Latitude & Cycl-oplegia \\
\hline Norway & $16-19$ & 393 & 13 & 0.5 & 57 & $60.4^{\circ} \mathrm{N}$ & YES \\
\hline North India & $9-12$ & 516 & 27 & NA & NA & $16.4^{\circ} \mathrm{N}$ & YES \\
\hline \multirow[t]{2}{*}{ Brazilian } & $9-11$ & 266 & 6.4 & NA & 67.1 & $22.9^{\circ} \mathrm{S}$ & YES \\
\hline & $13-15$ & 167 & 12.6 & & 59.8 & & \\
\hline Poland & $9-13$ & 4875 & 14.01 & NA & NA & $52.1^{\circ} \mathrm{N}$ & YES \\
\hline Denmark & $9.7-15.4$ & 307 & 17.9 & NA & NA & $55.8^{\circ} \mathrm{N}$ & YES \\
\hline France & $10-19$ & 8289 & 42.7 & 1.8 & NA & $48.7^{\circ} \mathrm{N}$ & NO \\
\hline Korea & $5-19$ & 7486 & 51.9 & 5.0 & 13.4 & $37.3^{\circ} \mathrm{N}$ & NO \\
\hline Netherlands & 6 & 5711 & 2.4 & NA & NA & $53.2^{\circ} \mathrm{N}$ & YES \\
\hline Saudi Arabia & $3-10$ & 1,893 & 2.7 & NA & 1.5 & $24.3^{\circ} \mathrm{N}$ & NO \\
\hline Colombia & 15 & NA & 14.7 & NA & 32.3 & $5.1^{\circ} \mathrm{N}$ & NO \\
\hline Spain & $5-7$ & 6152 & 20 & 3.6 & NA & $43.4^{\circ} \mathrm{N}$ & $\mathrm{NO}$ \\
\hline Indonesia & $8-12$ & 410 & 32.68 & 8.54 & 0.73 & $6.1^{\circ} \mathrm{S}$ & NO \\
\hline Eastern China & 18 & 43,858 & 87.65 & 16.6 & NA & $29.4^{\circ} \mathrm{N}$ & $\mathrm{NO}$ \\
\hline Eastern China & $10-15$ & 4890 & 52.02 & 5.7 & NA & $36.0^{\circ} \mathrm{N}$ & YES \\
\hline Northern China & $6-18$ & 35,745 & 70.9 & 19.4 & NA & $40.2^{\circ} \mathrm{N}$ & $\mathrm{NO}$ \\
\hline Southern China & $7.2-12.2$ & 1669 & 69.9 & 3.1 & NA & $23.2^{\circ} \mathrm{N}$ & $\mathrm{NO}$ \\
\hline Western China & $6-15$ & 1858 & 54.9 & 2.42 & 3.0 & $29.0 \mathrm{~N}$ & YES \\
\hline Northern China & $6-12$ & 527 & 53.9 & NA & NA & $38^{\circ} \mathrm{N}$ & YES \\
\hline Eastern China & $5-19$ & 4801 & 63.1 & 9.4 & NA & $29.02^{\circ} \mathrm{N}$ & $\mathrm{NO}$ \\
\hline Our study & $6-15$ & 31,524 & 45.97 & 0.96 & 13.80 & $20^{\circ} \mathrm{N}$ & NO \\
\hline
\end{tabular}




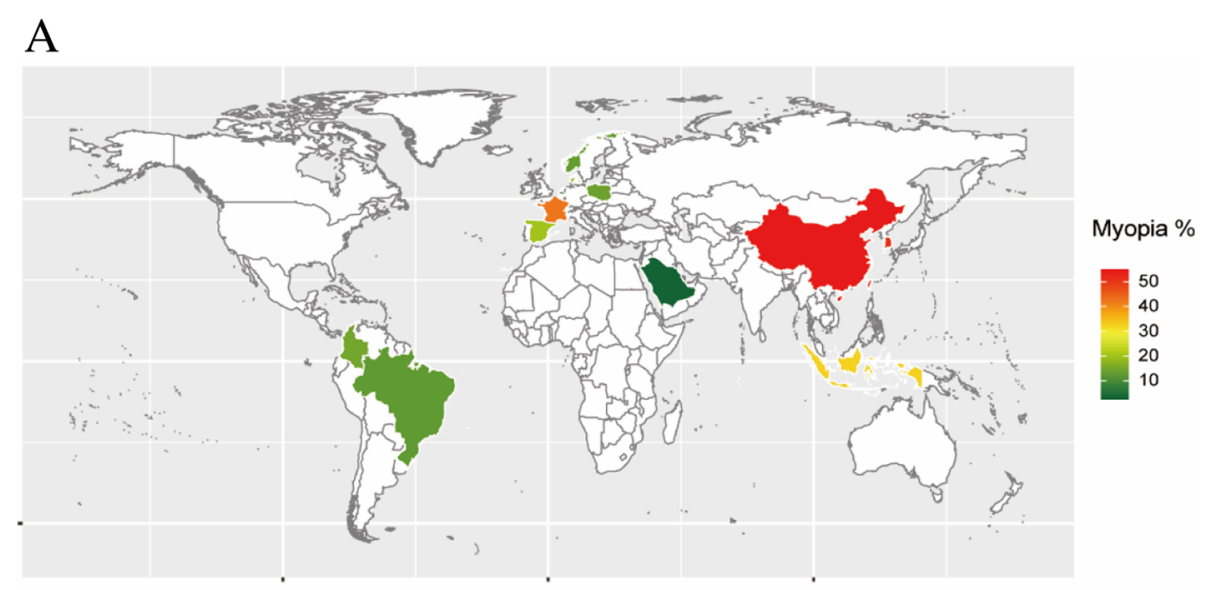

B

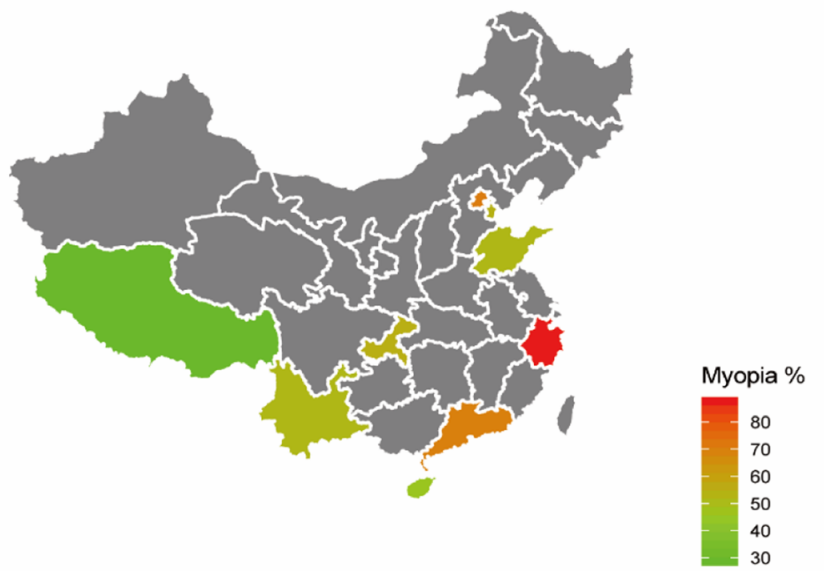

Fig. 5 Map of World a and China $\mathbf{b}$ showing the data of myopia prevalence from other studies published in recent 5 years, matched on myopia definition and age

(3.6\%) [11], Indonesia (8.54\%) [27], and the aforementioned Chinese cities. The overall prevalence of hyperopia ( $\mathrm{SE} \geq+0.50 \mathrm{D})(13.8 \%)$ is significantly higher than Indonesia(0.73\%) [27], America(5\%) [28], and Chongqing (3\%, Western China) [23]; Significantly lower than Norway (57.0\%) [7], Brazil (59.8\%) [29], and Colombia (32.3\%) [14]. However, it is similar to Korea (13.4\%) [18]. A thorough comparison of refractive error based on studies published during the last 5 years is summarized in Table 3.

Mean SE in our study was better than Guangzhou $(-1.7 \pm 1.9$ D) [20], Tianjin $(-0.99 \pm 1.69$ D) [24], in 612 year-olds, and Yiwu $(-2.61 \pm 2.01 \mathrm{D})$ [30], in 12 yearolds. It was however worse than Poland $(+0.55 \pm 1.23 \mathrm{D})$ [16], and Norway $(+0.51 \pm 1.29 \mathrm{D})$ [7]. In this study, the trends of different SE were also calculated. The trends showed a low ratio of $\mathrm{SE} \leq-5.00$ and $\mathrm{SE} \leq-6.00$. This indicated another feature that although myopia was common, it could develop into high myopia slowly (Fig. 5).

The exact mechanism associated with myopia was undetermined, but could be explained by many related factors, such as genetic factors, environment, lower refractive status at baseline, shorter reading distance, outdoor exposure and so on. Overall, increased incidence of myopia remains a global public health challenge, which necessitates novel therapeutic methods to curb its progression.

Even though genetic factors are considered to be important in myopia development, especially high myopia $[9,31]$, a multitude of studies on the large increase in incidence propose a much stronger effect of environmental factors in younger students. Some researchers hold the view that intensive continuing education and limited time outdoors are major risk factors [32]. However, little evidence of the relationship between time spent at work and myopia was reported in Norway [7]. This is important as Norway has a low myopia prevalence and being outdoors is a part of growing up. Many of the studies on myopia suggest that longer outdoor light exposure time correlated with a significant reduction in myopia prevalence and incidence among school students [11]. High levels of daylight exposure were considered to be the 
environmental factor of greatest importance in preventing myopia [33]. Haikou City, as the capital of Hainan Province, located in low-latitude tropical regions in China, experiences China's longest hours of sunshine and great radiant energy. The average sunshine hours are more than $2000 \mathrm{~h}$ per year. The hypothesis that daylight exposure explains why prevalence of myopia in our study was lower than other regions of China cannot explain why it was higher than other countries at the same latitude, such as North India [6]. In addition, at the same latitude, the incidence rate of myopia was higher than in other Asian children of the same age, but with lower high myopia prevalence [18]. Therefore, daylight exposure may be an influential factor, but it does not fully explain myopia development.

Results of another study showed that increased computer use is related to myopia development before children reach 10 years of age. Outdoor exposure may be important for intervention against myopia because it could mitigate near work activities, including computer use, reading time and distance [34]. A systematic review of several studies has indicated an association between screen time and myopia, but Meta-analysis suggested that screen time was not related with prevalent and incident myopia. So, there is still a debate whether digital screen time would induce the higher risk of myopia [35]. However, there is no question that more near work and less time spent outdoors would be affected by the increased use of digital devices.

As mentioned in the literature review, previous studies have noted the importance of UVB exposure in myopia. Increased UVB exposure reduces myopia, especially in adolescence [36]. Violet light suppressed the axial length elongation in the chick myopia model, and myopia suppressive gene EGR1 was upregulated as revealed by expression microarray analyses [37]. Several reports have shown that the increasing quartile of total UVB can contribute to decreased prevalence of myopia [38].

Hainan, with the longer time of UV exposure, is the smallest and southernmost province of China. As compared to many studies conducted in other provincial capital cities of China, low overall myopia prevalence (46.0\%) and low overall high myopia prevalence (1.0\%) were found in our screening population. In addition, numbers of nonmyopic students newly developing myopia annually are lower. The possible reasons for this difference may be associated with environmental influences. It is likely that the UVB exposure is one of the important factors in myopia development.

Our study contributes new knowledge to the field attributed to the latest and large population-based screening methods. When we defined refractive errors, monocular myopia, hyperopia and astigmatism were taken into consideration rather than performing statistical analyses on one of two eyes. Our approach thus represents the overall data unlike reports in other published papers. Our calculated myopia prevalence would therefore be artificially lower than now reported if we simulated the alternative approach from such studies.

Although myopia was defined as combined spherical equivalent with normal UCVA to reduce over-measuring of myopic magnitude, there is still a notable limitation of the present study. There is lack of cycloplegic refraction that might lead to over-estimation of myopia and under-estimation of hyperopia due to accommodation. The difference in refractive error prior to, and after cycloplegia was about 0.37 diopters in a small sample; consistent with other research findings [23]. Regardless, the difference between pre- and post-cycloplegia was small and may not impose a significant clinical influence under real-world conditions in a large sample population. We also need further investigations to acquire data on ocular biometry and more detailed information about students. We certainly aim for this to be our next research focus.

Genetic and environmental risk factors may be taken into consideration to explain how refractive errors develop differently. Our results presented a higher myopia prevalence than European countries, which indicated the potential presence of a genetic predisposition to myopia in Asian populations. All in all, myopia in Asians is a serious health problem. Genetic heterogeneity, variation in circannual adaptation and environmental factors including timing and behavior patterns of exposure to myopia-generation are related to greater shift towards myopia. Therefore, it is important to dedicate effective control methods to slow myopia progression.

\section{Conclusions}

Myopia was the most common refractive error in southernmost province in China (Hainan). Its prevalence increased with age, while hyperopia prevalence showed a decreasing trend. However, myopia, especially high myopia prevalence was much lower than in other urban regions across China, as residents of Hainan may benefit from more ultraviolet $B$ (UVB) radiation during daylight exposure.

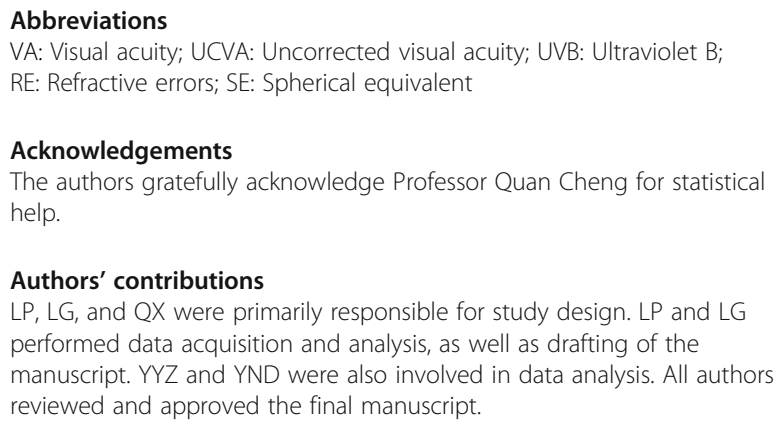

Authors' contributions

$L P, L G$, and $Q X$ were primarily responsible for study design. $L P$ and $L G$ performed data acquisition and analysis, as well as drafting of the manuscript. YYZ and YND were also involved in data analysis. All authors reviewed and approved the final manuscript. 


\section{Funding}

The authors are thankful for the financial support of Hainan Provincial Classification of Project No: ZDYF2020110.

\section{Availability of data and materials}

The data used to support the findings of this study are available from the corresponding author upon request.

\section{Declarations}

\section{Ethics approval and consent to participate}

This study was approved by the research ethics committees of Central South University Xiangya School of Medicine, Affiliated Haikou Hospital and adhered to the tenets of the Declaration of Helsinki (Ethical Approval Number: SC20200141). Informed consent was obtained from their parent or legal guardian of all participants.

\section{Consent for publication}

$$
\text { Not applicable. }
$$

\section{Competing interests}

The authors declare that there is no conflict of interest regarding the publication of this paper.

\section{Author details}

${ }^{1}$ Department of Ophthalmology, Central South University Xiangya School of Medicine Affiliated Haikou Hospital, Haikou 570208, Hainan, China. ${ }^{2}$ Department of Ophthalmology, The Second Xiangya Hospital, Central South University, Changsha 410000, Hunan, China. ${ }^{3}$ Department of Neurosurgery, Central South University Xiangya School of Medicine Affiliated Haikou Hospital, Haikou 570208, Hainan, China. ${ }^{4}$ Department of Ophthalmology, Changsha Central Hospital, University of South China, Changsha 410004, Hunan, China.

Received: 24 February 2021 Accepted: 10 May 2021 Published online: 20 May 2021

\section{References}

1. Fricke TR, Jong M, Naidoo KS, Sankaridurg P, Naduvilath TJ, Ho SM, Wong TY, Resnikoff S. Global prevalence of visual impairment associated with myopic macular degeneration and temporal trends from 2000 through 2050: systematic review, meta-analysis and modelling. Br J Ophthalmol. 2018;102(7):855-62.

2. Williams KM, Verhoeven VJ, Cumberland P, Bertelsen G, Wolfram C, Buitendijk GH, Hofman A, van Duijn CM, Vingerling JR, Kuijpers RW, et al. Prevalence of refractive error in Europe: the European Eye Epidemiology (E(3)) Consortium. Eur J Epidemiol. 2015;30(4):305-15.

3. Morjaria P, Evans J, Gilbert C. Predictors of spectacle wear and reasons for nonwear in students randomized to ready-made or custom-made spectacles: results of secondary objectives from a randomized noninferiority trial. JAMA Ophthalmology. 2019;137(4):408-14.

4. Morgan IG, Ohno-Matsui K, Saw SM. Myopia. Lancet. 2012;379(9827):173948.

5. Naidoo KS, Fricke TR, Frick KD, Jong M, Naduvilath TJ, Resnikoff S, Sankaridurg P. Potential lost productivity resulting from the global burden of myopia: systematic review, meta-analysis, and modeling. Ophthalmology. 2019;126(3):338-46.

6. $\quad$ Singh NK, James RM, Yadav A, Kumar R, Asthana S, Labani S. Prevalence of myopia and associated risk factors in schoolchildren in North India. Optom Vis Sci. 2019;96(3):200-5.

7. Hagen LA, Gjelle JVB, Arnegard S, Pedersen HR, Gilson SJ, Baraas RC. Prevalence and possible factors of myopia in Norwegian adolescents. Sci Rep. 2018;8(1):13479.

8. Cai XB, Shen SR, Chen DF, Zhang Q, Jin ZB. An overview of myopia genetics. Exp Eye Res. 2019;188:107778.

9. Tideman JWL, Polling JR, Jaddoe WW, Vingerling JR, Klaver CCW. Environmental risk factors can reduce axial length elongation and myopia incidence in 6- to 9-year-old children. Ophthalmology. 2019;126(1):127-36.

10. Pärssinen O, Kauppinen M. Risk factors for high myopia: a 22-year follow-up study from childhood to adulthood. Acta Ophthalmol. 2019;97(5):510-8.
11. Alvarez-Peregrina CC, Sanchez-Tena M, Martinez-Perez CC, Villa-Collar CC. Prevalence and risk factors of myopia in Spain. J Ophthalmol. 2019;2019: 3419576.

12. O'Donoghue L, Rudnicka AR, McClelland JF, Logan NS, Saunders KJ. Visual acuity measures do not reliably detect childhood refractive error-an epidemiological study. PLOS ONE. 2012;7(3):e34441.

13. Alrahili NHR, Jadidy ES, Alahmadi BSH, Abdula'al MF, Jadidy AS, Alhusaini AA, Mojaddidi MA, Al-Barry MA. Prevalence of uncorrected refractive errors among children aged 3-10 years in western Saudi Arabia. Saudi Med J. 2017;38(8):804-10.

14. Galvis V, Tello A, Otero J, Serrano AA, Gómez LM, Camacho PA, LópezJaramillo JP. Prevalence of refractive errors in Colombia: MIOPUR study. Br J Ophthalmol. 2018;102(10):1320-3.

15. Lundberg K, Suhr Thykjaer A, Søgaard Hansen R, Vestergaard AH, Jacobsen N, Goldschmidt E, Lima RA, Peto T, Wedderkopp N, Grauslund J. Physical activity and myopia in Danish children-The CHAMPS Eye Study. Acta Ophthalmol. 2018:96(2):134-41.

16. Czepita M, Czepita D, Safranow K. Role of gender in the prevalence of myopia among polish schoolchildren. J Ophthalmol. 2019;2019:9748576.

17. Matamoros E, Ingrand P, Pelen F, Bentaleb Y, Weber M, Korobelnik JF, Souied E, Leveziel N. Prevalence of myopia in France: a cross-sectional analysis. Medicine. 2015;94(45):e1976.

18. Rim TH, Kim SH, Lim KH, Choi M, Kim HY, Baek SH. Refractive errors in Koreans: The Korea National Health and Nutrition Examination Survey 20082012. Korean J Ophthalmol. 2016;30(3):214-24.

19. Chen M, Wu A, Zhang L, Wang W, Chen X, Yu X, Wang K. The increasing prevalence of myopia and high myopia among high school students in Fenghua city, eastern China: a 15-year population-based survey. BMC Ophthalmol. 2018;18(1):159.

20. Wang SK, Guo Y, Liao C, Chen Y, Su G, Zhang G, Zhang L, He M. Incidence of and factors associated with myopia and high myopia in Chinese children, based on refraction without cycloplegia. JAMA Ophthalmol. 2018;136(9): 1017-24.

21. Guo $Y$, Duan JL, Liu LJ, Sun $Y$, Tang $P, L V Y Y, X u L$, Jonas JB. High myopia in Greater Beijing School Children in 2016. PLoS ONE. 2017;12(11):e0187396.

22. Sun JT, An M, Yan XB, Li GH, Wang DB. Prevalence and related factors for myopia in school-aged children in Qingdao. J Ophthalmol. 2018;2018: 9781987.

23. Zhou WJ, Zhang YY, Li H, Wu YF, Xu J, Lv S, Li G, Liu SC, Song SF. Five-year progression of refractive errors and incidence of myopia in school-aged children in Western China. J Epidemiol. 2016;26(7):386-95.

24. Liu S, Ye S, Wang Q, Cao Y, Zhang X. Breastfeeding and myopia: a crosssectional study of children aged 6-12 years in Tianjin, China. Sci Rep. 2018; 8(1): 10025 .

25. Qian DJ, Zhong H, Li J, Niu Z, Yuan Y, Pan CW. Myopia among school students in rural China (Yunnan). Ophthalmic Physiol Opt. 2016;36(4):381-7.

26. Qian X, Liu B, Wang J, Wei N, Qi X, Li X, Li J, Zhang Y, Hua N, Ning Y, et al. Prevalence of refractive errors in Tibetan adolescents. BMC Ophthalmol. 2018;18(1):118.

27. Mahayana IT, Indrawati SG, Pawiroranu S. The prevalence of uncorrected refractive error in urban, suburban, exurban and rural primary school children in Indonesian population. Int J Ophthalmol. 2017;10(11):1771-6.

28. Wajuihian SO, Hansraj R. Refractive error in a sample of black high school children in South Africa. Optom Vis Sci. 2017;94(12):1145-52.

29. Lira RP, Arieta CE, Passos TH, Maziero D, Astur GL, do Espírito Santo ÍF, Bertolani AC, Pozzi LF, de Castro RS, Ferraz ÁA. Distribution of ocular component measures and refraction in Brazilian School Children. Ophthalmic Epidemiol. 2017;24(1):29-35.

30. Wang J, Ying GS, Fu X, Zhang R, Meng J, Gu F, Li J. Prevalence of myopia and vision impairment in school students in Eastern China. BMC Ophthalmol. 2020;20(1):2

31. Wu PC, Huang HM, Yu HJ, Fang PC, Chen CT. Epidemiology of myopia. AsiaPac J Ophthalmol. 2016;5(6):386-93.

32. Morgan IG, French AN, Ashby RS, Guo X, Ding X, He M, Rose KA. The epidemics of myopia: aetiology and prevention. Prog Retin Eye Res. 2018;62:134-49.

33. Ho CL, Wu WF, Liou YM. Dose-response relationship of outdoor exposure and myopia indicators: a systematic review and meta-analysis of various research methods. Int J Environ Res Public Health. 2019;16(14):2595.

34. Enthoven CA, Tideman JWL, Polling JR, Yang-Huang J, Raat H, Klaver CCW. The impact of computer use on myopia development in childhood: The Generation R study. Prev Med. 2020;132:105988. 
35. Lanca C, Saw SM. The association between digital screen time and myopia: a systematic review. Ophthalmic Physiol Opt. 2020;40(2):216-29.

36. Williams KM, Bentham GC, Young IS, McGinty A, McKay GJ, Hogg R, Hammond CJ, Chakravarthy U, Rahu M, Seland J, et al. Association between myopia, ultraviolet $B$ radiation exposure, serum vitamin $\mathrm{D}$ concentrations, and genetic polymorphisms in vitamin D metabolic pathways in a multicountry European Study. JAMA Ophthalmol. 2017;135(1):47-53.

37. Torii H, Kurihara T, Seko Y, Negishi K, Ohnuma K, Inaba T, Kawashima M, Jiang $\mathrm{X}$, Kondo S, Miyauchi M, et al. Violet light exposure can be a preventive strategy against myopia progression. EBioMedicine. 2017;15:2109.

38. Sherwin JC, Hewitt AW, Coroneo MT, Kearns LS, Griffiths LR, Mackey DA. The association between time spent outdoors and myopia using a novel biomarker of outdoor light exposure. Invest Ophthalmol Vis Sci. 2012;53(8): 4363-70.

\section{Publisher's Note}

Springer Nature remains neutral with regard to jurisdictional claims in published maps and institutional affiliations.

Ready to submit your research? Choose BMC and benefit from:

- fast, convenient online submission

- thorough peer review by experienced researchers in your field

- rapid publication on acceptance

- support for research data, including large and complex data types

- gold Open Access which fosters wider collaboration and increased citations

- maximum visibility for your research: over $100 \mathrm{M}$ website views per year

At BMC, research is always in progress.

Learn more biomedcentral.com/submissions 